\title{
Bottom-Gate Complementary Inverters on Plastic with Gravure-Printed Dielectric and Semiconductors
}

\author{
Nikolay L. Vaklev, Ying Yang, Beinn V. O Muir, Joachim H. G. Steinke and Alasdair J. Campbell
}

\begin{abstract}
Organic complementary circuitry combines all the advantages of plastic electronics, such as flexibility, thinness and solution-processability with low power consumption. Here we report organic complimentary inverters fabricated in a carrierfree batch process on plastic foil with dielectric and semiconductor layers patterned using the high-volume gravure contact printing technique. The transistor components have bottom-gate, bottom-contact configuration with aluminium gates and gold contacts, allowing full use of photolithographic processing whilst protecting the semiconductors by depositing them last. Cross-linkable polymer dielectric, p-type small molecule and the n-type polymer semiconductors are printed from inks based on non-chlorinated solvents. Printing instability is observed for capillary numbers approaching 1 . The $430 \mathrm{~nm}$ thick dielectric affords relatively-low operational voltage and it is the thinnest printed organic dielectric reported in the literature for organic inverters to date. Both p- and n-type transistors have a mobility of $0.01-0.04 \mathrm{~cm}^{2} \mathrm{~V}^{-1} \mathrm{~s}^{-1}$. The device parameters for the n-type transistors show less variation than the p-type transistors, which can be related to the more isotropic charge transport in polymer films compared to the small-molecule polycrystalline films. The resultant inverters have an average gain of $4.5 \pm 1.5$ and a maximum gain of 8 at $V_{D D}=-20 \mathrm{~V}$. The combination of conventional photolithographic processing and gravure contact printing can therefore be used to fabricate bottom-gate organic complementary circuitry on plastic.
\end{abstract}

Index Terms-printing gravure, complementary inverters, organic transistors

\section{INTRODUCTION}

Organic electronic circuits on plastic substrates have the potential advantages of flexibility and thinness. High-volume low-cost printing methods such as gravure printing can be used to fabricate uniform layers over large areas. There are two types of inverters - unipolar and complementary based on the type of semiconductors they use. Unipolar inverters[1] require only one semiconductor whereas complementary logic need both p- and n-type semiconductors. Complementary inverters consume power only during switching between states. They also have much higher noise margins (NMs), which is advantageous for designing digital circuits, and improves device yield.

N. L. Vaklev was with the Physics Department of Imperial College London. (e-mail: nikolay.vaklev@gmail.com). Y. Yang is with the Chemistry department of Imperial College London (e-mail: y.yang@imperial.ac.uk) B. V. O. Muir was with the Physics department of Imperial College London (email: beinnmuir@gmail.com). J. H. G. Steinke was professor at the Chemistry department of Imperial College London. A. J. Campbell is with the Physics department of Imperial College London (e-mail: alasdair.campbell@imperial.ac.uk).
RFID tags[2] in packaging, flexible displays[3], wearable electronics[4], [5], optical[6] and biomedical[7], [8] sensors have been demonstrated with transistors based on organic materials. A microprocessor based on unipolar circuits was reported on plastic foil fabricated using standard photolithography and thermally evaporated p-type semiconductor.[9] Schmidt et al.[10] also showed fullyprinted unipolar p-type inverters and ring-oscillators reaching $1.0 \mathrm{kHz}$. On the other hand, there has been a delay in the development of complementary organic circuits due to the lack of commercially-available n-type organic semiconductors (OSCs) other than fullerenes and their derivatives. In 2009, Yan et al.[11] demonstrated an n-type polymer based on a naphthalene diimide monomer and it is used in this work.

Organic electronics opens the possibility to partially or fully print devices and circuits. Printing techniques are especially advantages in the fabrication of complementary inverters, because they allow direct patterning of the semiconductors. In the case of organic inverters two organic semiconductors have to be deposited onto the same substrate. This requirement presents a particular limitation for blanketcoating techniques such as spin-casting, zone-casting and blade-coating. It is possible to establish a process flow based on additive and subtractive steps to pattern semiconductors, but increasing the number of processing steps is inefficient and leads to low yields. Printing techniques such as ink-jet, gravure, and offset-lithography allow one or more inks to be selectively printed onto the same substrate. Kempa et al.[12] reported fully-printed complementary inverters and ring oscillators with gain around 5 and $1.5 \mu \mathrm{m}$ thick dielectric printed using flexography and semiconductors printed using gravure. Jacob et al. [13] provided another example of fullyprinted complementary inverters with screen-printed dielectric and printed semiconductors with a gain of 15-20.

We reported recently high-performance flexible bottomgate bottom-contact (BGBC) organic field-effect transistors.[14] The dielectric was gravure-coated over the whole substrate and defined by photopatterning. Here we use gravure printing to directly structure the dielectric and both semiconductors to build complementary inverters on plastic foil, which eliminates the need for additional patterning. All inks are based on industry-compatible non-chlorinated solvents and give appropriately defined features. Unlike previous complementary circuits ${ }^{11-13}$, we use a bottom-gate configuration. This configuration is preferred by industry because it allows full use of photolithographic processing whilst protecting the semiconductors from UV light and 
aggressive chemicals by depositing them last. Devices are fabricated in a carrier-free sheet-to-sheet batch process flow. The resultant inverters achieve average gain of 5 at low operating voltage of $-20 \mathrm{~V}$. This work demonstrates also one of the thinnest printed dielectrics $(430 \mathrm{~nm})$ for complementary inverters and BGBC transistors (Fig. 1) with short channel lengths of 5-25 $\mu \mathrm{m}$ (Table A.1), both of which lower drive voltages and improve circuit speed. General device fabrication is described elsewhere[14] and brief summary of the fabrication process is provided in Supplemental Materials.

(a)

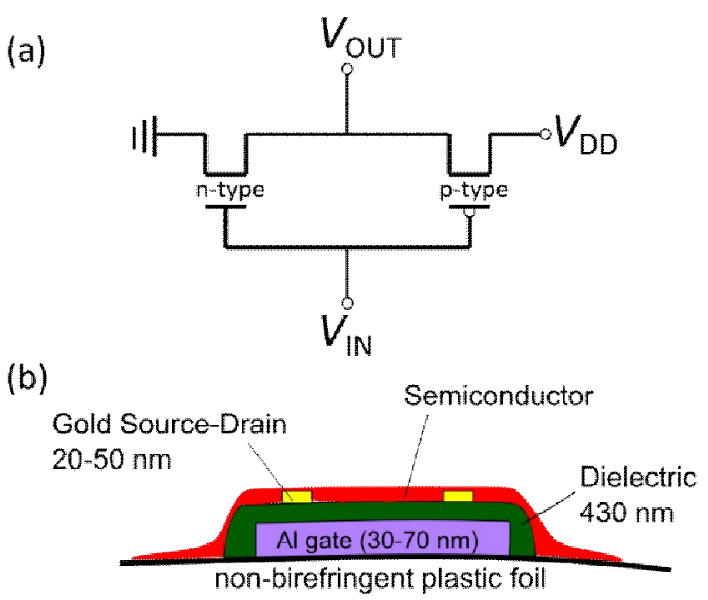

(b)

(c)

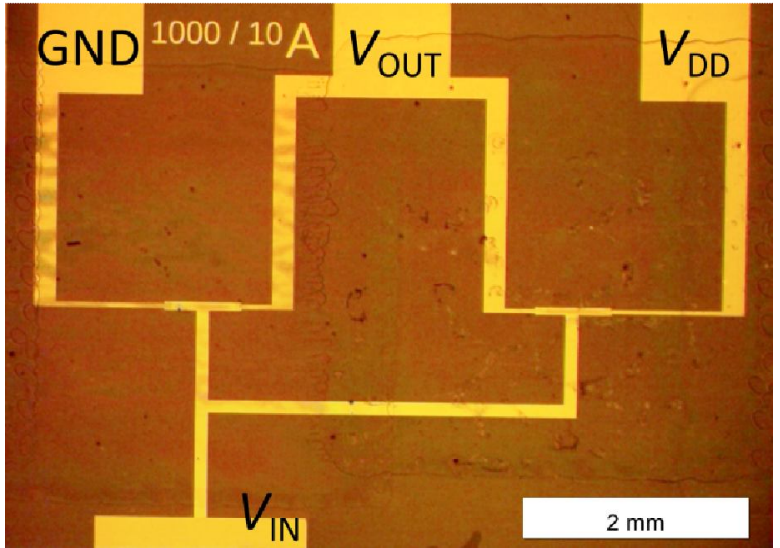

(d)

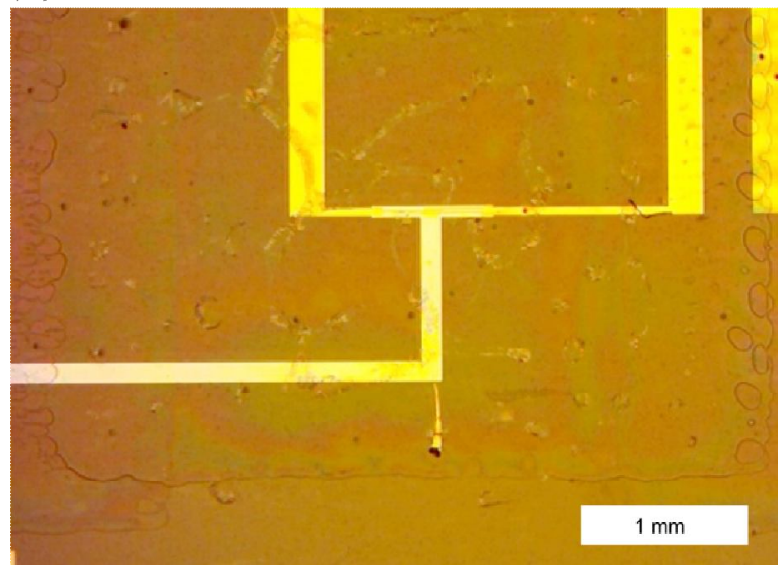

Fig. 1. (a) Diagram of a complementary inverter; the drive voltage is connected to the p-type. (b) Diagram of transistor cross-section. (c) Optical micrograph with annotations of a complementary inverter on plastic substrate. (d) Optical micrograph of p-type transistor.
Achieving printed uniform and functional films is one of the main questions for printed electronics. In this study, print speed and screen density were varied, and, viscosity and surface tension investigated. Print screen density is defined as the number of ink cell lines per unit length on the printing plate. The printing parameters were aggregated in capillary ( $\mathrm{Ca}$ ) and Reynolds (Re) numbers and compared (Fig. A.1). The $C a$ number is associated with the liquid meniscus formed between substrate and cliché around the nip during ink transfer[15], whereas the $R e$ number represent the balance between inertial and viscous forces.

\section{MATERIALS AND METHODS}

A proprietary non-birefringent plastic foil from Asulab (Switzerland) with pre-deposited transparent conducting oxide (TCO) was used. The glass-transition temperature of the material was $215^{\circ} \mathrm{C}$ and the maximum processing temperature was $180^{\circ} \mathrm{C}$. The substrates were cleaned by sonication and the TCO was etched away. The gate electrode was made by thermal evaporation of aluminium $(30-70 \mathrm{~nm})$ followed by photolithographic patterning and etching. The dielectric was gravure printed on top, annealed and crosslinked with UV radiation. The dielectric formulation is a proprietary material from BASF which contains an acrylate cross-linker (42 wt\%), a high molecular weight poly(methyl methacrylate) (4.2 wt\%) as a viscosity modifier and two highboiling-point solvents. The radical photoinitiator Irgacure 369 from BASF was added to the dielectric formulation at $10 \mathrm{mg} \mathrm{mL}^{-1}$ prior to printing. The films were dried at $115^{\circ} \mathrm{C}$ for $5 \mathrm{~min}$ in ambient air and cross-linked under nitrogen in Novascan PSDP-UV for $10 \mathrm{~min}$. Contacts and interconnects were fabricated on top by thermal evaporation of gold (30$90 \mathrm{~nm}$ ) and patterning via photolithography and bilayer liftoff. The printed semiconductors were 6,13bis(triisopropylsilylethynyl) pentacene (TIPS-pentacene, High Force Research, UK) and P(NDI2OD-T2) n-type (ActiveInk N2200, Polyera Corporation, USA). The n-type OSC was printed first and annealed for $30 \mathrm{~s}$ at $115^{\circ} \mathrm{C}$, followed by printing the p-type. All solvents were purchased from Aldrich. Printing was done with a Schlaefli Maschinen Labratester 1 at $160 \pm 40 \mathrm{~N} \mathrm{~cm}^{-2}$ nip pressure. This process flow uses carrierfree batch processing, which is compatible with many industrial processes and photolithography of the metal electrodes is a standard industrial technique. Viscosity and surface tension for the different inks were measured with PAC VISCOlab 4000 and Krüss DSA 100, respectively. Printing specifications and ink parameters are reported in Table A.2.

\section{RESULTS AND DISCUSSION}

The dielectric was printed at three different print speeds in the range $12-44 \mathrm{~m} / \mathrm{min}$ while keeping the other parameters constant. Print screen density was fixed at 40 lines $\mathrm{cm}^{-1}$ to achieve the necessary film thickness. Continuous film coverage was obtained only at $12 \mathrm{~m} / \mathrm{min}$ (Fig. 2), which was the lowest speed possible with the printer. At higher print speeds, there was a regular pattern of holes in the dielectric films, which correlated with the pits of the print screen. The organic dielectric layer used in the inverters (print speed 12 $\mathrm{m} \mathrm{min}^{-1}$ ) was $430 \pm 17 \mathrm{~nm}$ thick as measured by contact profilometry and the relative permittivity was 3.2 based on 
impedance spectroscopy[14]. The root-mean-square surface roughness was $14 \mathrm{~nm}$ as measured by optical interferometry over an area of $1 \times 1 \mathrm{~mm}^{2}$ (Fig. A.2). The off-currents for all transistors were $1-10 \mathrm{pA}$ demonstrating the quality of the printed dielectric and the on/off ratio was in the range $10^{4}-10^{6}$ (Fig. A.3 and Fig. A.4). The $\mathrm{Ca}$ and Re numbers were found to be in the range $0.2-1$ and $0.04-0.2$, respectively, with the most uniform printed films used in the inverters having the lowest values (Fig. A.1). For comparison, Li et al. reported recently gravure-printing $300 \mathrm{~nm}$ thick organic semiconductor in diodes.[16] The dielectric reported here is exposed to higher electric field in the transistors.

TIPS-pentacene was printed from $10 \mathrm{mg} \mathrm{mL}^{-1}$ (ca. $1 \mathrm{wt} \%)$ solution in anisole:decane (99.5:0.5 v/v\%) solvent mixture. Print screen density was fixed at 250 lines $\mathrm{cm}^{-1}$ to achieve thin TIPS-pentacene films with a low transistor offcurrent. This ink gave continuous coverage whereas the equivalent ink based on pure anisole produced incomplete coverage at $12 \mathrm{~m} \mathrm{~min}^{-1}$ and separate TIPS-pentacene crystals at $44 \mathrm{~m} \mathrm{~min}^{-1}$ (Fig. 3). The surface tension of decane and anisole is 23 and $35 \mathrm{mN} \mathrm{m}^{-1}$ at room temperature, respectively.[17] Decane accumulates at the liquid-air interface and lowers the surface tension of the solvent mixture, which is driven by a decrease in the Gibbs free energy of the system.[18] Experimentally, adding decane lowered the surface tension from $30 \pm 2$ to $26 \pm 2 \mathrm{mN} \mathrm{m}^{-1}$ (Table A.2) in pendant-drop measurements. The estimated $\mathrm{Ca}$ numbers during printing were in the range of 0.01 . The TIPSpentacene ink with decane gave continuous films with crystalline domains. The viscosity was ca. $1 \mathrm{cP}$ for these inks, which is approximately the intrinsic viscosity of the pure organic solvents. Therefore, their properties were determined by surface tension and the way it affected meniscus formation and stability around the nip. This result confirms again that printing at low capillary numbers stabilises ink transfer. The Reynolds number appears to have less of an effect in the investigated range of $0.01-10$.

(a) $12 \mathrm{~m} / \mathrm{min}$

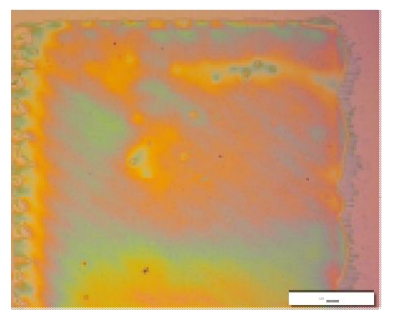

(c) $44 \mathrm{~m} / \mathrm{min}$

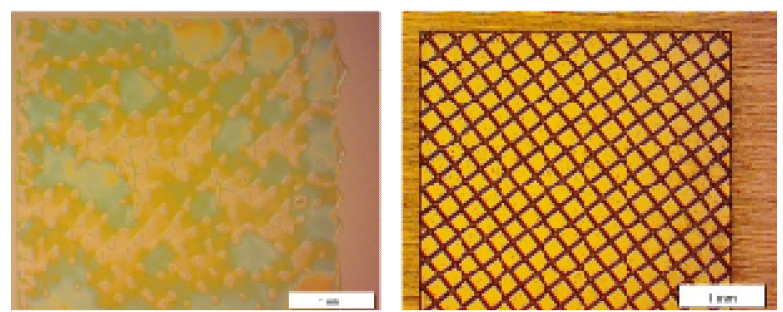

Fig. 2. Optical micrographs of $(a, b, c)$ the dielectric ink printed at three different print speeds with (d) 40 line $\mathrm{cm}^{-1}$ print screen. Scale bar $1 \mathrm{~mm}$. (a) $12 \mathrm{~m} / \mathrm{min}$

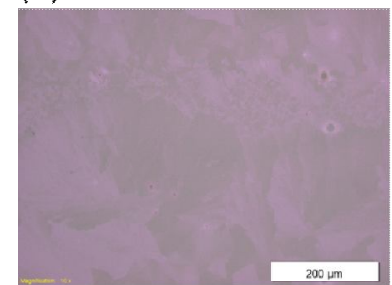

(c) $12 \mathrm{~m} / \mathrm{min}$

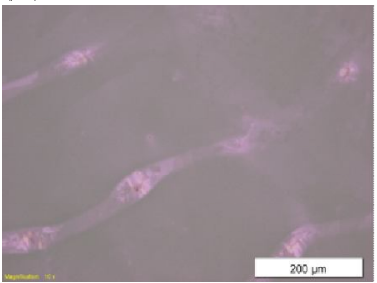

Fig. 3. Optical micrographs of the TIPS-pentacene printed from $(a, b)$ anisole:decane $(99.5: 0.5 \mathrm{v} / \mathrm{v} \%)$ mixture and (c, d) pure anisole at 12 and $44 \mathrm{~m} \mathrm{~min}^{-1}$ print speed on the dielectric. Decane improved ink transfer and afforded continuous coverage at all speeds.

The n-type polymer OSC P(NDI2OD-T2) was deposited from a solvent mixture of tetrahydronaphthalene:indane $\left(50: 50 \mathrm{v} / \mathrm{v} \%\right.$ ) at a concentration of $20 \mathrm{mg} \mathrm{mL}^{-1}$ (ca. $2 \mathrm{wt} \%$ ). A higher printing speed of $40 \mathrm{~m} / \mathrm{min}$, similar to that used with the successful TIPS-pentacene inks, was used. The print screen density at constant speed was varied. The different ink loading per area was used as a characteristic length to calculate the $R e$ number for the different print screens. Hence, changing the screens for the n-type ink at constant speed resulted in the same $C a$ number but different $R e$ values. At $C a$ and $R e$ of ca. 1 and 0.1 , respectively, the prints exhibited patterns of "cascade" instability[19], [20] (Fig. 4), which is associated with the meniscus formation and stability around the nip region; the ink forms a wetting meniscus between cliché and substrates during printing.[21], [22] The n-type and the dielectric inks have similar $R e$ numbers but differ in their loading with the dielectric having ca. 20-times higher solid content by mass and the 5-times lower capillary number. These results show that when $\mathrm{Ca}$ approaches 1 the ink transfer becomes unstable, resulting in non-uniform films and cascade patterns. However, surface roughness and non-uniformity of the semiconducting films are not an issue for BGBC transistors as long as the coverage is a few nanometres thick to allow a complete accumulation layer to form between source and drain; this property is a strong advantage of the BGBC architecture. Films printed using a screen density of 250 lines $\mathrm{cm}^{-1}$ were used in devices, combining complete coverage with a low transistor off current. 
(a) 40 line/cm

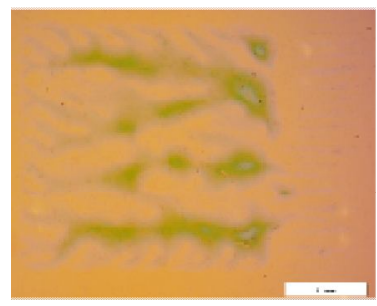

(c) 200 line/cm (b) 100 line $/ \mathrm{cm}$

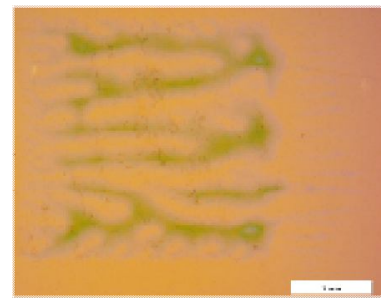

(d) 250 line/cm
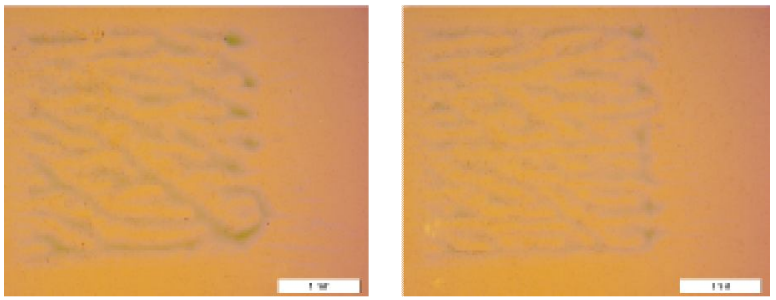

Fig. 4. Optical micrographs of the n-type ink printed with four different print screens on PC-TCO. The micrographs show inhomogeneous ink pattern known as "cascade instability". The print direction is from left to right. Scale bar $1 \mathrm{~mm}$.

OFETs with both semiconductors had negligible hysteresis in the transfer curves (Fig. 5). Charge-carrier mobility and threshold voltage in the saturation regime were extracted from the linear fit to $V_{\mathrm{gs}}$ vs. $\left(I_{\mathrm{ds}}\right)^{1 / 2}$ (Table A.1).[14] The hole and electron mobilities were on average 0.036 and $0.013 \mathrm{~cm}^{2} \mathrm{~V}^{-1} \mathrm{~s}^{-1}$, respectively. The spread though for TIPSpentacene was an order of magnitude higher than for the ntype. This is most likely a result of the crystalline nature of TIPS-pentacene (Fig. 5c), which is known to have anisotropic transport.[23], [24] The n-type is a semi-crystalline polymer[25] and the average transport properties should be isotropic. These results underline the necessity for precise control of the crystallinity for small molecules. Nevertheless, the upper limit for the p-type mobility was ca. $0.1 \mathrm{~cm}^{2} \mathrm{~V}^{-1} \mathrm{~s}^{-1}$ which is comparable to the best examples in the literature for BGBC devices with TIPS-pentacene.[26] The P(NDI2OD-T2) n-type showed ambipolar behaviour clearly seen in the eleveated off-currents in the saturation regime (Fig. 5b), which has been observed by other authors.[27], [28] The inverters were stored and measured in a nitrogen glovebox ( $0.1 \mathrm{ppm}$ oxygen and water) otherwise the n-type had mobility $<10^{-4} \mathrm{~cm}^{2} \mathrm{~V}^{-1} \mathrm{~s}^{-1}$ or no transistor performance altogether. A typical inverter curve is shown on Fig. 6. The averaged maximum gain was $4.5 \pm 1.5$ at $V_{\mathrm{DD}}=-20 \mathrm{~V}$ based on 12 inverters $(60 \%$ yield $)$. The highest maximum gain achieved was 8 (Fig. A.5a). However, there was scatter in the NM values (Fig. A.5b). This can be related to the spread in mobility and threshold voltage values for the p-type combined with the ambipolar transport of the n-type.

(a)

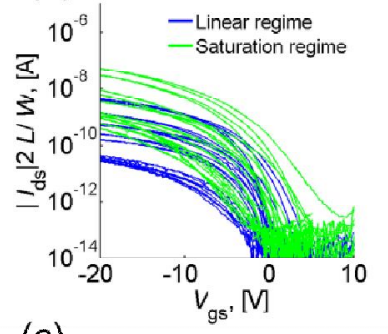

(c)

(b)

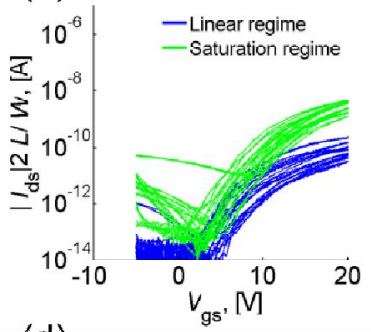

(d)

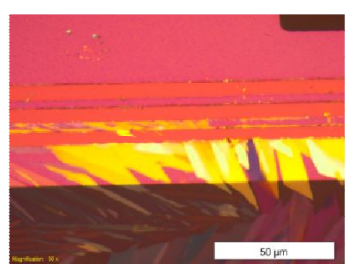

Fig. 5. Transfer curves of OFETs with (a) p- and (b) n-type semiconductors. The $V_{\mathrm{ds}}$ for linear and saturation regimes were \pm 5 and $\pm 20 \mathrm{~V}$, respectively. Voltage polarity depended on the semiconductor type. Optical micrographs of the printed (c) p- and (d) n-type in the transistor channel obtained with crosspolariser. Scale bar $50 \mu \mathrm{m}$.

\section{CONCLUSIONS}

In conclusion, we fabricated bottom-gate inverters on plastic with gravure-printed dielectric and semiconductors. Printing instability increases for capillary numbers approaching 1; the Reynolds numbers had no appreciable effect on the printing process within the investigated range. The dielectric layer is $430 \mathrm{~nm}$ thick and exhibited ultra-low leakage levels; it is the thinnest printed dielectric reported in the literature to date in inverters. The p-type small-molecule semiconductor OFETs had a large parameter spread and the $\mathrm{n}$ type exhibited ambipolar behavior, which resulted in a large spread of noise margin values. However, an average gain of 4.5 at relatively low drive voltage of $20 \mathrm{~V}$ was achieved, with a peak gain value of 8 . These results show the potential of gravure printing and this bottom-gate batch process flow for the fabrication of flexible complementary inverters. Gravure was used to print inks with variable solid content and viscosity demonstrating its versatile nature.

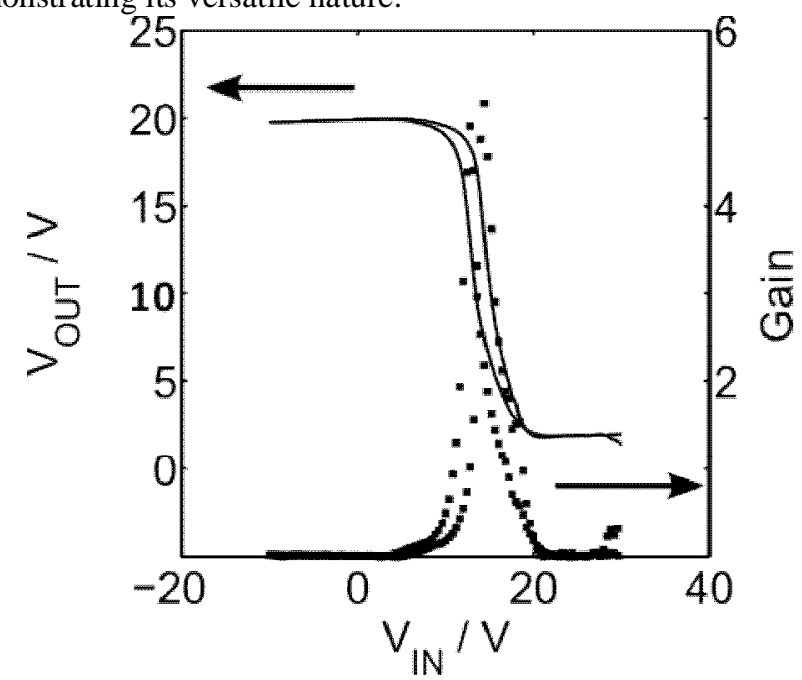

Fig. 6. Inverter characteristic of an average device with low and high noise margins of 10 and $-5 \mathrm{~V}$ at $V_{\mathrm{DD}}=-20 \mathrm{~V}$. 
APPENDIX A. SUPPLEMENTARY INFORMATION

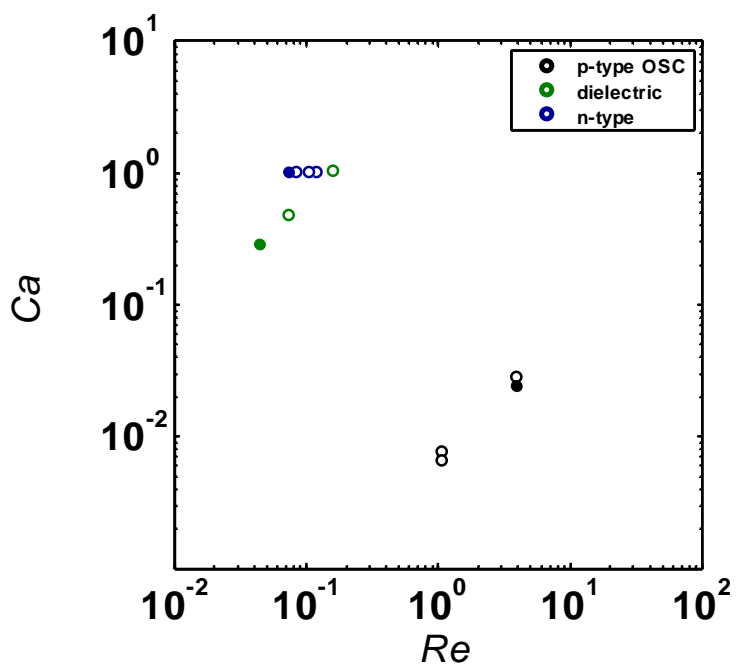

Fig. A.1. Capillary $(\mathrm{Ca})$ vs. Reynolds $(\mathrm{Re})$ numbers for the prints shown on Fig. 2, Fig. 3 and Fig. 4. The filled circles correspond to the different inks printed in the inverters. A summary of all printing parameters for the final inks is given in Table A.2.

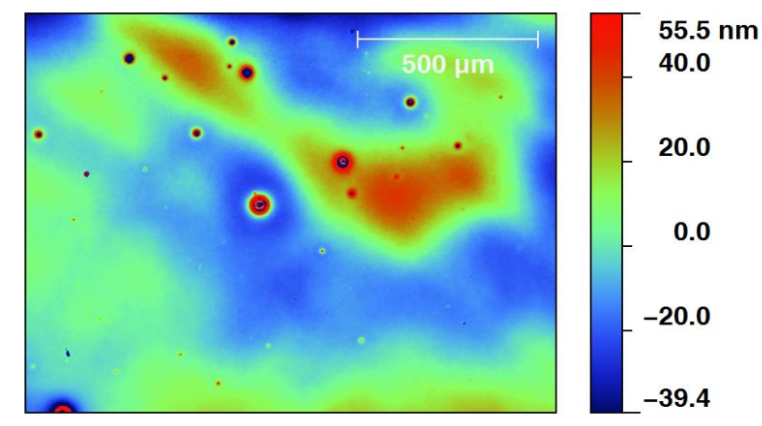

Fig. A.2. Optical-interferometry micrograph of the dielectric ink printed at $12 \mathrm{~m} \mathrm{~min}^{-1}$. The rounds dots are from particle contamination on the foil. The rms surface roughness was $14 \mathrm{~nm}$, excluding artifacts due to particle contamination.
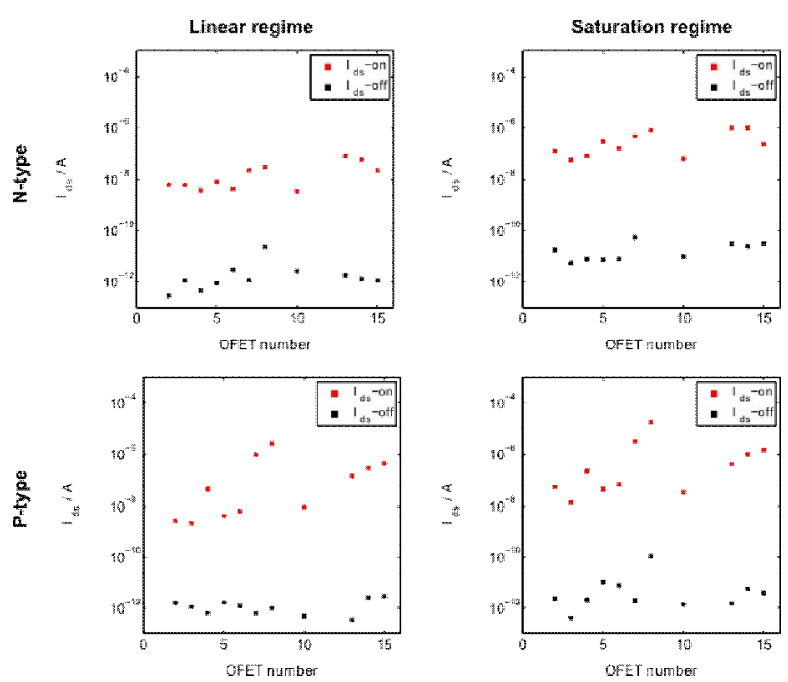

Fig. A.3. Source-drain current in on- and off-state for linear and saturation regimes for OFETs with gravure printed $\mathrm{p}$ - and $\mathrm{n}$-type semiconductors and dielectric. The current is not adjusted for the $W / L$ ratio of the transistors.

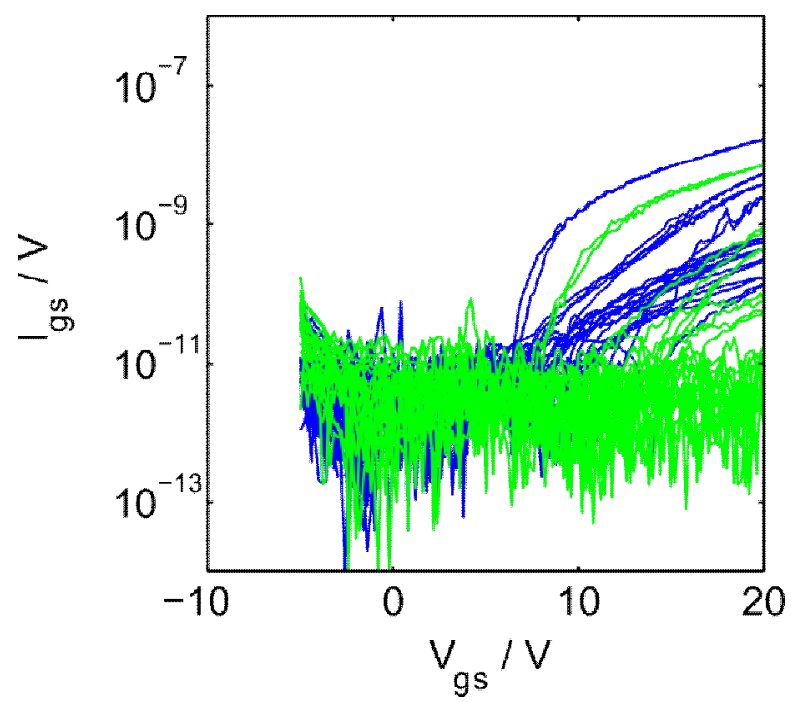

Fig. A.4. Gate-source current for linear and saturation regime for n-type OFETs.
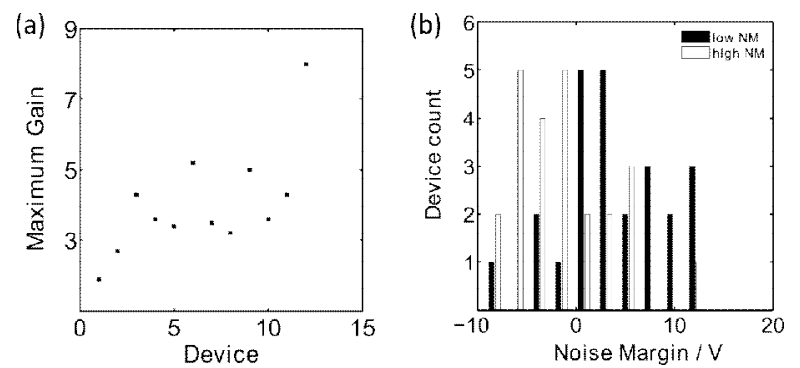

Fig. A.5. (a) Maximum gain and (b) their noise margins for 12 inverters. The noise margins are calculated as described in Ref. [29] at -0.5 gain.

\section{ACKNOWLEDGMENT}

The research leading to these results has received funding from the European Community's Seventh Framework Programme (FP7/2007-2013) under grant agreement $\mathrm{n}^{\circ} 247978$. The authors would like to thank Dr Anne A. Y. Guilbert for her constructive feedback.

\section{REFERENCES}

K. Myny, M. J. Beenhakkers, N. A. J. M. van Aerle, G. H. Gelinck, J. Genoe, W. Dehaene, and P. Heremans, "Unipolar organic transistor circuits made robust by dual-gate technology," IEEE J. Solid-St. Circ., vol. 46, no. 5, pp. 1223-1230, 2011.

[2] K. Myny, S. Steudel, S. Smout, P. Vicca, F. Furthner, B. van der Putten, A. K. Tripathi, G. H. Gelinck, J. Genoe, and W. Dehaene, "Organic RFID transponder chip with data rate compatible with electronic product coding," Org. Electron., vol. 11, no. 7, pp. 11761179, Jul. 2010.

[3] G. Gelinck, P. Heremans, K. Nomoto, and T. D. Anthopoulos, "Organic transistors in optical displays and microelectronic applications.," Adv. Mater., vol. 22, no. 34, pp. 3778-3798, Sep. 2010. 
C. Zysset, T. Kinkeldei, N. Münzenrieder, L. Petti, G. A. Salvatore, and G. Tröster, "Combining electronics on flexible plastic strips with textiles," Text. Res. J., vol. 83, no. 11, pp. 1130-1142, Jul. 2013

Y. Yang, R. C. da Costa, M. J. Fuchter, and A. J. Campbell,

"Circularly polarized light detection by a chiral organic

semiconductor transistor," Nat. Photon., vol. 7, no. 8, pp. 634-638, Aug. 2013

X. Guo, M. Myers, S. Xiao, M. Lefenfeld, R. Steiner, G. S. Tulevski, J. Tang, J. Baumert, F. Leibfarth, J. T. Yardley, M. L. Steigerwald, P. Kim, and C. Nuckolls, "Chemoresponsive monolayer transistors.," P. Natl. Acad. Sci. USA, vol. 103, no. 31, pp. 11452-11456, Aug. 2006.

M. E. Roberts, S. C. B. Mannsfeld, N. Queraltó, C. Reese, J. Locklin, W. Knoll, and Z. Bao, "Water-stable organic transistors and their application in chemical and biological sensors.," $P$. Natl. Acad. Sci. USA, vol. 105, no. 34, pp. 12134-12139, Aug. 2008.

K. Myny, E. Van Veenendaal, G. H. Gelinck, J. Genoe, W. Dehaene, and P. Heremans, "An 8-Bit, 40-Instructions-Per-Second Organic Microprocessor on Plastic Foil," IEEE J. Solid-St. Circ., vol. 47, no. 1, pp. 284-291, 2012.

[10] G. C. Schmidt, D. Höft, M. Bhuie, K. Haase, M. Bellmann, F Haidu, D. Lehmann, D. R. T. Zahn, and a. C. Huebler, "Modified poly(3,4-ethylenedioxythiophene):poly(styrenesulfonate) source/drain electrodes for fully printed organic field-effect transistors consisting of a semiconductor blend," Appl. Phys. Lett. vol. 103, no. 11, p. 113302, 2013.

[11] H. Yan, Z. Chen, Y. Zheng, C. Newman, J. R. Quinn, F. Dötz, M. Kastler, and A. Facchetti, "A high-mobility electron-transporting polymer for printed transistors.," Nature, vol. 457, no. 7230, pp. 679-686, Feb. 2009

[12] H. Kempa, M. Hambsch, K. Reuter, M. Stanel, G. Schmidt, B. Meier, and A. Huebler, "Complementary Ring Oscillator Exclusively Prepared by Means of Gravure and Flexographic Printing," IEEE T. Electron Dev., vol. 58, no. 8, pp. 2765-2769, 2011

[13] S. Jacob, M. Benwadih, J. Bablet, I. Chartier, R. Gwoziecki, S. Abdinia, E. Cantatore, L. Maddiona, F. Tramontana, G. Maiellaro, L. Mariucci, G. Palmisano, and R. Coppard, "High performance printed N and P-type OTFTs for complementary circuits on plastic substrate," in Solid-State Device Research Conference (ESSDERC), 2012 Proceedings of the European, 2012, pp. 173-176.

[14] N. L. Vaklev, R. Müller, B. V. O. Muir, D. T. James, R. Pretot, P. van der Schaaf, J. Genoe, J.-S. Kim, J. H. G. Steinke, and A. J. Campbell, "High-Performance Flexible Bottom-Gate Organic FieldEffect Transistors with Gravure Printed Thin Organic Dielectric," Adv. Mater. Interfaces, vol. 1, no. 3, p. 1300123, Feb. 2014

[15] C. A. Powell, M. D. Savage, and P. H. Gaskell, "Modelling the Meniscus Evacuation Problem in Direct Gravure Coating," Trans. IChemE, vol. 78, no. 1, pp. 61-67, Jan. 2000

[16] M. Li, P. S. Heljo, and D. Lupo, "Organic rectifying diode and circuit for wireless power harvesting at $13.56 \mathrm{MHz}$," IEEE Trans. Electron. Dev., vol. 61, no. 6, pp. 2164-2169, 2014.
[17] W. M. Haynes, T. J. Bruno, and D. R. Lide, Eds., "Surface Tension of Common Liquids," in Handbook of Chemistry and Physics, 95th ed., CRS Press, 2014, pp. 6-182-6-185.

[18] A. W. Adamson and A. P. Gast, "The Nature and Thermodynamics of Liquid Interfaces," in Physical Chemistry of Surfaces, 6th ed., John Wiley $\backslash \&$ Sons, 1997, pp. 48-100.

[19] D. J. Coyle, C. W. Macosko, and L. E. Scriven, "The fluid dynamics of reverse roll coating," AIChE J., vol. 36, no. 2, pp. 161174, Feb. 1990.

[20] W. Pulkrabek and J. D. Munter, "Knurl roll design for stable rotogravure coating," Chem. Eng. Sci., vol. 38, no. 8, pp. 1309$1314,1983$.

[21] N. Kapur, "A parametric study of direct gravure coating," Chem. Eng. Sci., vol. 58, no. 13, pp. 2875-2882, Jul. 2003.

[22] R. W. Hewson, N. Kapur, and P. H. Gaskell, "A theoretical and experimental investigation of tri-helical gravure roll coating," Chem. Eng. Sci., vol. 61, no. 16, pp. 5487-5499, Aug. 2006.

[23] D. T. James, B. K. C. Kjellander, W. T. T. Smaal, G. H. Gelinck, C. Combe, I. McCulloch, R. Wilson, J. H. Burroughes, D. D. C. Bradley, and J.-S. Kim, "Thin-Film Morphology of Inkjet-Printed Single-Droplet Organic Transistors Using Polarized Raman Spectroscopy: Effect of Blending TIPS-Pentacene with Insulating Polymer.," ACS Nano, vol. 5, no. 12, pp. 9824-9835, Dec. 2011.

[24] D. T. James, J. M. Frost, J. Wade, J. Nelson, and J.-S. Kim "Controlling Microstructure of Pentacene Derivatives by Solution Processing - Impact of Structural Anisotropy on Optoelectronic Properties.," ACS Nano, vol. 7, no. 9, pp. 7983-7991, Aug. 2013

[25] J. Rivnay, M. F. Toney, Y. Zheng, I. V Kauvar, Z. Chen, V. Wagner, A. Facchetti, and A. Salleo, "Unconventional face-on texture and exceptional in-plane order of a high mobility n-type polymer.," Adv. Mater., vol. 22, no. 39, pp. 4359-4363, Oct. 2010.

[26] B. K. C. Kjellander, W. T. T. Smaal, K. Myny, J. Genoe, W. Dehaene, P. Heremans, and G. H. Gelinck, "Optimized circuit design for flexible 8-bit RFID transponders with active layer of inkjet printed small molecule semiconductors," Org. Electron., vol. 14, no. 3, pp. 768-774, Mar. 2013

[27] K.-J. Baeg, J. Kim, D. Khim, M. Caironi, D.-Y. Kim, I.-K. You, J. R. Quinn, A. Facchetti, and Y.-Y. Noh, "Charge injection engineering of ambipolar field-effect transistors for highperformance organic complementary circuits.," ACS Appl. Mater. Interfaces, vol. 3, no. 8, pp. 3205-3214, Aug. 2011.

[28] K.-J. Baeg, D. Khim, S.-W. Jung, M. Kang, I.-K. You, D.-Y. Kim, A. Facchetti, and Y.-Y. Noh, "Remarkable enhancement of hole transport in top-gated N-type polymer field-effect transistors by a high-k dielectric for ambipolar electronic circuits.," Adv. Mater. vol. 24, no. 40, pp. 5433-5439, Oct. 2012.

[29] R. C. Jaeger and T. N. Blalock, "Intorduction to digital electronics," in Microelectronic circuit design, 4th ed., M. Lange, Ed. New York: McGraw-Hill, 2011, pp. 287-366. 
Table A.1. Comparison between the present work and a selection of literature sources. The inverters are compared in terms of transistor architecture, logic type, hole $\left(\mu_{\mathrm{h}}\right)$ and electron $\left(\mu_{\mathrm{e}}\right)$ mobility, drive voltage $\left(V_{\mathrm{DD}}\right)$, gain, dielectric thickness $(d)$ for the p- and n-type semiconductors where appropriate.

\begin{tabular}{|c|c|c|c|c|c|c|c|c|c|}
\hline Ref. & OFET & Logic type & $\mu_{\mathrm{h}} / \mathrm{cm}^{2} \mathrm{~V}^{-1} \mathrm{~s}^{-1}$ & $\mu_{\mathrm{e}} / \mathrm{cm}^{2} \mathrm{~V}^{-1} \mathrm{~s}^{-1}$ & $\begin{array}{l}V_{\mathrm{DD}} \\
/ \mathrm{V}\end{array}$ & Gain & $d / \mu \mathrm{m}$ & $\begin{array}{l}\text { Dielectric } \\
\text { deposition }\end{array}$ & OSC deposition \\
\hline here & BGBC & complementary & $0.001-0.1^{\mathrm{b}}$ & $0.01-0.06^{\mathrm{b}}$ & -20 & $2-8$ & 0.43 & gravure & gravure \\
\hline [2] & $\mathrm{BGBC}^{\mathrm{a}}$ & unipolar & 0.15 & NA & 10 & - & - & spin-casting & spin-casting \\
\hline$[10]$ & TGBC & unipolar & 0.2 & NA & $>48$ & - & 2 & gravure & screen print \\
\hline$[11]$ & TGBC & complementary & $0.02-0.1$ & $>0.1$ & 20 & 50 & 1 & gravure & gravure \\
\hline [12] & TGBC & complementary & 0.004 & 0.003 & -60 & 5.3 & 1.5 & flexography & gravure \\
\hline [13] & TGBC & complementary & 1.5 & 0.55 & 40 & $15-20$ & 0.75 & screen print & unknown \\
\hline
\end{tabular}

${ }^{\mathrm{a}}$ The devices had a top gate as well, which allows control of the threshold voltage.

${ }^{\mathrm{b}}$ Measured in saturation regime.

$\mathrm{BGBC}=$ bottom-gate bottom-contact BCTG = bottom-contact top-gate

Table A.2. Summary of ink and printing parameters: solvent composition, surface tension $(\gamma)$, viscosity $(\eta)$, print speed, print screen density, ink loading of the print screen and, $R e$ and $C a$ numbers.

\begin{tabular}{|c|c|c|c|c|c|c|c|c|c|}
\hline V. Ink & Solvent 1 & Solvent 2 & $\begin{array}{c}\gamma \\
/ \mathrm{mN} \mathrm{m}^{-1}\end{array}$ & $\begin{array}{l}\eta^{\mathrm{d}} \\
/ \mathrm{cP}\end{array}$ & $\begin{array}{l}\text { Print speed } \\
\quad / \mathrm{m} \mathrm{min}\end{array}$ & $\begin{array}{l}\text { Print Screen } \\
\text { /line } \mathrm{cm}^{-1}\end{array}$ & $\begin{array}{l}\text { Ink loading } \\
/ \mathrm{nL} \mathrm{mm}\end{array}$ & $\operatorname{Re}$ & $\mathrm{Ca}$ \\
\hline n-type $\left(20 \mathrm{mg} \mathrm{mL}^{-1}\right)$ & $\begin{array}{c}\text { Indane } \\
(50 \mathrm{v} / \mathrm{v} \%)\end{array}$ & $\begin{array}{c}\text { THN } \\
(50 \mathrm{v} / \mathrm{v} \%)\end{array}$ & $32 \pm 2$ & 48 & 40 & 250 & 5.3 & 0.073 & 1.0 \\
\hline \multicolumn{10}{|l|}{ TIPS-pentacene } \\
\hline$\left(10 \mathrm{mg} \mathrm{mL}^{-1}\right)$ & Anisole & - & $30 \pm 2^{b}$ & $\sim 1^{\mathrm{b}}$ & 44 & 250 & 5.3 & 3.9 & 0.024 \\
\hline \multicolumn{10}{|l|}{ TIPS-pentacene } \\
\hline$\left(10 \mathrm{mg} \mathrm{mL}^{-1}\right)$ & $\begin{array}{c}\text { Anisole } \\
(99.5 \mathrm{v} / \mathrm{v} \%)\end{array}$ & $\begin{array}{c}\text { Decane } \\
(0.5 \mathrm{v} / \mathrm{v} \%)\end{array}$ & $26 \pm 2^{b}$ & $\sim 1^{\mathrm{b}}$ & 44 & 250 & 5.3 & 3.9 & 0.028 \\
\hline Dielectric ink & - & - & 28 & 40 & 12 & 40 & 8.7 & 0.043 & 0.29 \\
\hline
\end{tabular}

${ }^{a}$ preferred print speed

${ }^{\mathrm{b}}$ pure solvent mixtures

${ }^{\mathrm{c}}$ Ink loading per print screen was used as a characteristic length to calculate the $R e$ numbers.

${ }^{\mathrm{d}}$ measured at $21-23{ }^{\circ} \mathrm{C}$.

Ink density was assumed $1 \mathrm{~g} \mathrm{~mL}^{-1}$ for all inks, which is a typical value for the used organic solvents. 